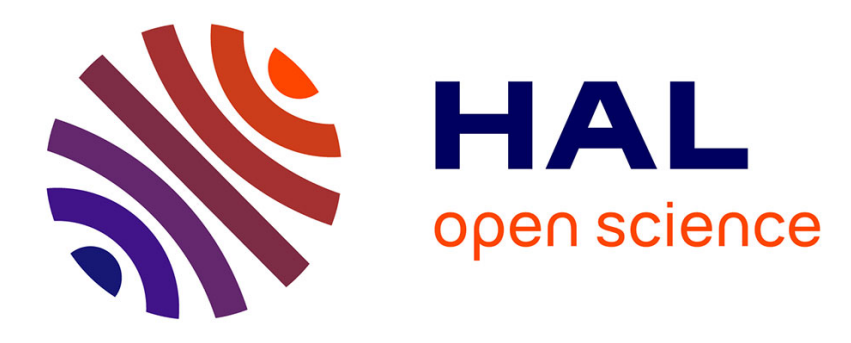

\title{
Das Gedächtnis des Horthy-Regimes und des Kommunismus in Ungarn

\author{
Catherine Horel
}

\section{To cite this version:}

Catherine Horel. Das Gedächtnis des Horthy-Regimes und des Kommunismus in Ungarn. Erinnerungskultur in Mittel- und Osteuropa. Die Auseinandersetzung mit Nationalsozialismus und Kommunismus im Vergleich, 2020. halshs-03090256

\section{HAL Id: halshs-03090256 \\ https://shs.hal.science/halshs-03090256}

Submitted on 29 Dec 2020

HAL is a multi-disciplinary open access archive for the deposit and dissemination of scientific research documents, whether they are published or not. The documents may come from teaching and research institutions in France or abroad, or from public or private research centers.
L'archive ouverte pluridisciplinaire HAL, est destinée au dépôt et à la diffusion de documents scientifiques de niveau recherche, publiés ou non, émanant des établissements d'enseignement et de recherche français ou étrangers, des laboratoires publics ou privés. 


\section{Das Gedächtnis des Horthy-Regimes und des Kommunismus in Ungarn CatherineHorel}

\section{Catherine Horel}

Die Erfahrung der Räterepublik (März-August 1919) stellt in Ungarn die erste Schicht in der Konstruktion einer Erinnerung an den Kommunismus dar. Die zweite wurde nach 1945 gebildet, erlitt jedoch einen großen Bruch zur Zeit der Revolution von 1956. Das KádárRegime (1956-1989) errichtete eine neue Gedenkkonstruktion, deren Grundlage die Leugnung der Revolution war, die mit massiver Auswanderung und brutaler Repression geendet hatte. Den zwei Momenten der kommunistischen Macht in Ungarn folgte jeweils die Ablehnung. Im Jahr 1920 war es das Werk der Alliierten und des Horthy-Regimes; 1956 ereignete es sich spontan und massiv durch einen allgemeinen Aufstand, auch der Arbeiter; 1989 drückt sich dies in einer Ablehnung des Systems als Ganzem durch die Gesellschaft und die politischen Eliten aus. Diese Demonstrationen scheinen die These zu bestätigen, dass der Kommunismus ein Regime ist, das in Ungarn grundsätzlich „fremd“ ist und dessen Versuche, ihn in die nationale Körperschaft dauerhaft zu transplantieren, nicht gelingen können. In der Tat interpretiert das Horthy-Regime den Bolschewismus als ein zweifaches Komplott, welches von der Fremde - Russland - und ihren Verbündeten und von Verrätern aus dem Innern - Juden - initiiert wurde. 1945 wie auch 1956 ist das Engagement der Sowjets offenkundig und muss nicht demonstriert werden, zumal es von der vorherigen Erfahrung und einer starken Russophobie aus dem vorigen Jahrhundert überlagert wird. ${ }^{1}$

In allen drei Episoden wird der Erinnerung eine wichtige Bedeutung zugewiesen. Die Räterepublik hatte jedoch zu wenig Zeit, Erinnerungsorte zu errichten, welche das folgende Regime hätte zerstören können. Die Erinnerung an das bolschewistische Experiment von 1919 wird von der kommunistischen Regierung nach 1945 formuliert, deren wichtiger erster Schritt die 100-Jahre-Gedenkfeier der 1848er-Revolution ist. Diese wird als Prämisse für den Sieg des Sozialismus interpretiert. Die Bevölkerung verurteilt diese Erinnerung allerdings als

\footnotetext{
${ }^{1}$ Während der Revolution und des Unabhängigkeitskriegs 1848-1849 sind es die Truppen von Zar Nikolaus I., die auf Wunsch von Kaiser Franz Josef die ungarische Armee (honvéd) besiegen. General Artur Görgey übergibt sich symbolisch den Russen und wird somit lange Zeit als Verräter betrachtet, bis die kommunistische Historiographie inn rehabilitiert, jedoch mit Mühe [Siehe den Ausstellungskatalog Az ismeretlen Görgey [Der unbekannte Görgey, Budapest, Magyar Nemzeti Múzeum, 2019].
} 
künstlich und darüber hinaus respektlos gegenüber den Werten, die während der Revolution beschworen wurden: Nationalismus und Liberalismus. Trotz der Einrichtung eines Nationalkommunismus, zu vergleichen mit den anderen Volksdemokratien, betrachteten viele Ungarn die Übernahme der Erinnerung an 1848 durch die Kommunisten als einen Verrat gegen die Nation. Einen Beweis dafür bildet die Parallele, die sie zwischen den Schicksalen von Lajos Batthyány, von den Österreichern am 6. Oktober 1849 erschossen, und jenem von Imre Nagy zogen, am 16. Juni 1958 auf Befehl der Sowjets gleichfalls hingerichtet. Das Budapester Denkmal für den Ersten wurde zu einem Treff- und Protestpunkt für das Andenken an den Zweiten, dessen Bestattungsort unbekannt war. ${ }^{2}$

Unter den Forderungen nach Veränderungen, die in der zweiten Hälfte der 1980er-Jahre lauter wurden, reihte sich das Thema des Erinnerns und damit der Anerkennung von Verbrechen, die im Namen der Ideologie begangen wurden, als eines der wichtigsten ein $^{3}$. Deswegen ist die Zeit nach 1989 von einer globalen Ablehnung der Symbole, Daten und Erinnerungsorte bestimmt, die das Land seit 1945 geprägt haben, und diese Ablehnung wird mit der Verweigerung von Lügen begründet. Es folgt eine „Rückkehr des Verdrängten“, die die als inakzeptabel empfundenen Figuren ebenso wie die sowjetische Inspiration wegfegt. Aber im Gegensatz zu 1919 sind die ehemaligen Führer teilweise die Akteure des Übergangs: Sie werden nicht verbannt, sind nicht eingesperrt. Die damnatio memoriae betrifft Symbole, Objekte, Orte, nicht aber die individuelle Erinnerung. ${ }^{4}$ In den 1990er-Jahren, nach den ersten Ernüchterungen der Wende, tauchte das kommunistische Gedächtnis allmählich wieder auf. So stellt 1996 die Feier des 40. Jahrestages von 1956 ein Problem für Gyula Horn und die sozialistische Regierung dar, da nicht wenige ihrer Mitglieder ehemalige Kader des KádárRegimes waren. ${ }^{5}$ Daher kann es nicht überraschen, dass die Erinnerung an 1956 immer wieder

\footnotetext{
${ }^{2}$ Das Denkmal von Móricz Pogány wurde 1926 errichtet. Es befindet sich an der Ecke Hold utca/Báthory utca, wo die Kaserne des „Neugebäudes“ stand. Im Innern brennt ein ewiges Licht (örökmécses).

${ }^{3}$ Horel, Catherine: Le rôle des lieux de mémoire dans la construction de la mémoire collective en Hongrie, in: Nagy, Piroska (Hrsg.) : Identités hongroises, identités européennes du Moyen Âge à nos jours, Publications des universités de Rouen et du Havre, 2006, S. 199-207.

${ }^{4}$ Es sei hier auf Maurice Halbwachs verwiesen, der von der differenzierten Erinnerung spricht, die Individuen von demselben Ereignis haben. Vgl. Halbwachs, Maurice: La mémoire collective, Paris: Albin Michel, 1997. Deutsche Übersetzung: Das kollektive Gedächtnis, Stuttgart: Enke, 1967.

${ }^{5}$ Ungváry, Krisztián: Orte der Erinnerung an kommunistische Verbrechen. Das „Haus des Terrors“ und der „Zentralfriedhof“, in: Weber, Matthias et al. (Hrsg.): Erinnerungsorte in
} 
von Viktor Orbán instrumentalisiert wird. Das Trauma der Revolution ist in der Bevölkerung noch virulent und wird in einer Weise übertragen, welche die Historiker in Frage stellen können, da sie feststellen müssen, wie das Phänomen in der langen Dauer der Erinnerung von 1848 eingeschrieben ist, deren Auswirkungen bis heute auf dem politischen Leben lasten. Der erste Teil dieses Beitrags untersucht den Prozess der Erinnerung, den Ungarn seit der ersten Erfahrung des Bolschewismus 1919 konstruiert hat. Er stellt die Frage nach der Entwicklung und potenziellen Ergänzung jenes Erinnerungsprozesses nach 1945, nach 1956 und schließlich nach 1989. Hat man es hier mit einer differenzierten Erinnerung zu tun und welches sind ihre Komponenten? Im zweiten Teil geht es um die Vergangenheitsbewältigung des nationalsozialistischen Regimes (1944-1945). Hier werden zwei Problematiken artikuliert: Die Bewertung des Horthy-Regimes (1920-1944) und jene der deutschen Besatzung. Die Frage der ungarischen Verantwortung (Kriegseintritt, Shoah) wurde schon 1945 diskutiert, bevor das kommunistische Regime alles unter dem Begriff der „Verbrechen gegen die Bürger" subsumierte und daher die Erinnerung an den Holocaust unmöglich machte. Jener Erinnerungsprozess konstituiert ein wichtiges Element der demokratischen Wende nach 1989.

\section{Der Kommunismus in Ungarn: eine unmögliche Erinnerung?}

In den Jahren nach der Einsetzung des kommunistischen Regimes dominieren in Ungarn drei Elemente in der Konstruktion des kommunistischen Gedächtnisses durch die Errichtung von Denkmälern und Gedenkstätten: Krieg und Sieg gegen den Faschismus; Ideologie (Statuen von Lenin und Stalin); ungarisch-sowjetische Freundschaft. Jene Aspekte sind tatsächlich transnational und finden sich, je nach Land des sozialistischen Blocks, angepasst an die Bedingungen des Nationalkommunismus. Das kommunistische Gedächtnis an die Zeit nach 1945 ist nicht nur eine „Revanche“ von 1919, sie setzt eine russisch-sowjetisch inspirierte Vulgata ein. In der Tat verhindert der Mangel an einer kommunistischen Vergangenheit in Ungarn die Betonung von zeitgenössischen Persönlichkeiten; die einzige qualifizierte, jene Béla Kuns, ist problematisch, da er im Laufe der Moskauer Schauprozesse liquidiert wurde. Der Personenkult, der Stalin und seinen ungarischen Klon MátyásRákósi hervorhebt, substituiert die Erinnerung an ein Ereignis der letzten Zeit, schlägt aber keine Wurzeln.

Ostmitteleuropa.Erfahrungen der Vergangenheit und Perspektiven, München: Oldenbourg, 2011, S. 219-233, hier S. 232. 
Deswegen wird es vorgezogen, Figuren aus einer älteren Vergangenheit zu glorifizieren, auch wenn es zugleich bedeutet, sie umzudeuten.

Im Rahmen der von der kommunistischen Regierung autorisierten Gedenkfeiern zeigt die Interpretation der Revolution von 1848, wie zweideutig der Umgang des Regimes mit der Nationalgeschichte ist. Nach den großen Feierlichkeiten zum hundertsten Jahrestag im Jahre 1948, in denen Rákosis Porträt zusammen mit jenen von Kossuth und Petőfi gezeigt wird, ${ }^{6}$ muss der 15. März schnell den wichtigeren Daten des Kalten Krieges weichen: dem 4. April, Jahrestag der Befreiung des Landes durch die Rote Armee, dem 1. Mai und dem 7. November, Gedenktag der Oktoberrevolution ${ }^{7}$. Laut der Interpretation der Partei ist die Revolution von 1848 ein Vorläufer der Volksdemokratie, deren zwei Hauptziele die Unterdrückung des Feudalismus und die Befreiung von der Fremdherrschaft waren. Somit sollten zum hundertjährigen Jubiläum folgende Lehren gezogen werden: die Verbindungen zwischen nationaler Unabhängigkeit und dem sozialen Aufstieg der Arbeiter; Kossuths Darstellung als demokratischer Führer der Revolution im Kampf gegen die Kräfte der habsburgischen und russischen Reaktion; dabei betont man zudem den Unterschied zwischen dem repressiven zaristischen Regime und der Sowjetunion; endlich die Wichtigkeit der nationalen Eintracht der Arbeiter und Bauern während des Unabhängigkeitskrieges ${ }^{8}$.

Die Botschaft des 15. März konnte potenziell Verlegenheit verursachen, welche 1956 dann auch tatsächlich ans Tageslicht kam. Die zweite ungarische Revolution beginnt tatsächlich mit der Mobilisierung der Vorstellungskraft der vorherigen. Die Forderungen der Zwölf Punkte der Petition von 1848 werden von den Demonstranten vom 23. Oktober 1956 wiederholt: Man spricht erneut von Presse- und Versammlungsfreiheit und vom Ende der Fremdherrschaft. Auch das Horthy-Regime musste sich mit der Bedeutung des 15. März abfinden; die Kommunisten konnten nicht anders, als das Datum weiterhin zu ehren. ${ }^{9}$ In

\footnotetext{
${ }^{6}$ Gerő, András: March 15th: The Fortunes of a National Day, in: The New Hungarian Quarterly, Nr. 126, Bd. 33, Sommer 1992, S. 113-123, hier S. 120.

${ }^{7}$ Der auf diesen Namen getaufte Budapester Platz wurde praktisch nie von den Einwohnern so bezeichnet, sondern weiterhin „Oktogon" genannt.

${ }^{8}$ Gyarmati, György: Március hatalma, a hatalom márciusa. Fejezetek március 15. ünneplésének történetéböl [Die Macht des März. Studien zur Geschichte der Feier zum 15. März], Budapest: Paginarum, 1998, S. 101.

${ }^{9} 1949$ hat man auch Gedenkfeiern zum Ende des Unabhängigkeitskriegs 1848-49 veranstaltet. Vgl. Gyarmati, Március hatalma, a hatalom márciusa, S. 107.
} 
regelmäßigen Abständen versuchten die Gegner des Regimes jedoch, den Tag gemäß einer anderen Bedeutung zu feiern, indem sie eine Demonstration entlang des historischen Wegs veranstalteten. 1972 und noch einmal 1987 versammelten sich Hunderte von Menschen im Garten des Nationalmuseums und gingen ohne Intervention der Polizei, die bloß zuschaute, zur Petőfi-Statue. Während der 1980er-Jahre ermutigte die zunehmende Liberalisierung des Regimes Meinungsverschiedenheiten. Am 15. März 1988 versammelten sich anlässlich des 140. Jahrestages der Revolution wieder etwa 10.000 Menschen vor dem Nationalmuseum. Die Polizeibehörden, überrascht von der Anzahl der Demonstranten, griffen nicht ein. Endlich wurde am 22. Februar 1989 beschlossen, den Tag des Nationalfeiertags vom 7. November auf den 15. März zu verschieben. Das erste offizielle und genehmigte Gedenken am 15. März war somit der Anlass eines großen patriotischen Jubels in Budapest und in den Provinzen. In der Hauptstadt führten die Züge, die von Mitgliedern der Opposition geleitet wurden, vom Nationalmuseum bis zum Petőfi-Denkmal und endeten vor dem Parlament. Gegenwärtig hat der 15. März wieder einen offiziellen Charakter, die Parade bleibt zwar eine populäre Feier, auf der nationale Lieder (Hymnusz, Szózat, Nemzeti Dal) gesungen werden, aber die Militärparade, die auf dem Kossuth-Platz stattfindet, gibt dem Tag einen eindeutig politischen Charakter, der nun von den Orbán-Gegnern heftig kritisiert wird.

Der Nationalfeiertag am 4. April, der an die Befreiung des Landes durch die Rote Armee erinnert, wird durch die Wiederherstellung des 15. März abgeschafft. Der Teil des kommunistischen Gedächtnisses, der durch seine Feiertage repräsentiert wird, ist sicherlich der Aspekt, der so schnell wie möglich aus dem kollektiven Bewusstsein verschwunden ist: Nur diejenigen, die vor 1989 ausgebildet und sozialisiert wurden, können sich noch an den 4. April und den 7. November erinnern. Das kommunistische Regime hatte seinerzeit auch den 20. August für sich beansprucht, indem es den Gedenktag des heiligen Königs Stefan in ein Fest der Verfassung und des neuen Brots (Erntefest) umgedeutet hatte. ${ }^{10}$ Die Wahl anderer nationaler Feiertage entspricht zwei Bedürfnissen: die religiösen Feiertage oder zumindest ihre Bedeutung als solche auszuradieren: Der Heilige Nikolaus wird in „Winter-Vati““ (Telapó) umbenannt; die anderen Daten des katholischen Kalenders verschwinden ${ }^{11}$. Der

\footnotetext{
${ }^{10}$ Horel, Catherine: Die Repression gegen die Kirchen in Ungarn und der Tschechoslowakei, in: Gehler, Michael/Luif, Paul/Vyslonzil, Elisabeth (Hrsg.): Die Dimension Mitteleuropa in der Europäischen Union. Geschichte und Gegenwart, Historische Europa Studien Band 20, Hildesheim: Olms Verlag, 2015, S. 137-156, hier S. 146.

${ }^{11}$ Romsics, Ignác: Magyarország története a XX. században [Geschichte Ungarns im 20. Jahrhundert], Budapest: Osiris, 1999, S. 357.
} 
Räterepublik von 1919 wird in den Jahren 1945-1947 nicht weiter gedacht, obwohl einige ihrer Symbole wiederbelebt werden, aber nicht unbedingt von der Kommunistischen Partei, wie ein Plakat der Sozialdemokratischen Partei zeigt, das das berühmte Motiv des „Roten Mannes“" von Mihály Biró aufgreift ${ }^{12}$. Nach dem Tode Stalins kann sich das Regime nun mehr erlauben und muss sich weniger schämen. Deswegen werden die Jubiläen der Räterepublik gebührend gefeiert. Die Säkularisierung beinhaltet auch die Verherrlichung des heidnischen Eroberers des Landes, Árpád, dessen Kult sich jenem um den heiligen König Stefan widersetzt.

Gleichzeitig bevorzugten die Kommunisten die Figur von Kossuth, der sie eine offensichtlich anachronistische Interpretation gaben. Um ihn in die marxistische Dialektik zu integrieren, wird anlässlich der Gedenkfeier für 1848 ein neues Denkmal errichtet. Es bildet ein gutes Beispiel für die Substitution der historischen Botschaft der Revolution. Kossuth und das gesamte Ereignis werden zu einem Teil der offiziellen Geschichtsschreibung, die sie als die wahren Vorläufer der nationalen Unabhängigkeit sieht (also mehr als die Räterepublik, die auch gescheitert ist), die nun, 1945, endlich erworben worden ist. Somit versuchen die Kommunisten noch einmal, die Vergangenheit zu ihren Gunsten umzuschreiben, indem sie das alte, während der Kämpfe des Winters 1944-45 beschädigte Denkmal durch ein neues Monument ersetzen. Der neue Diskurs entspricht den von der Partei erklärten Werten, die dazu schon als leitende Ideen der Revolution $1848-49$ betrachtet werden. ${ }^{13}$ Es war für das bisherige Regime schwierig gewesen, mit Kossuth und den anderen Protagonisten der Revolution abzurechnen. Aber die starke Identifikation der Bevölkerung mit ihnen und der Mangel an Symbolen, deren Notwendigkeit den Entscheidungsträgern des Horthy-Regimes nach den darauffolgenden Schocks von 1918-1919 bewusst war - abgesehen von dem ständigen revisionistischen Bezug auf die irredentistischen Länder -, führte zur Errichtung eines Denkmals zur Ehre der Revolution ${ }^{14}$. Das Denkmal, 1927 enthüllt, zeigt Kossuth

\footnotetext{
${ }^{12}$ Bakos, Katalin: Folyamatosság és törés a plakátművészetben [Kontinuität und Bruch in der Plakatkunst], in: Standeisky, Éva et al. (Hrsg.): A fordulat évei 1947-1949. Politika, képzőművészet, építészet, Budapest: 1956-os Intézet, 1998, S. 244.

${ }^{13} \mathrm{Horel}$, Catherine: La récupération des cultures nationales: le cas de la Hongrie, in: Sirinelli, JeanFrançois/Soutou, Georges-Henri (Hrsg.): Culture et guerre froide, Paris: PUPS, 2008, S. 27-38, hier S. 35.

${ }^{14}$ Horel, Catherine: Les lieux de mémoire à Budapest, entre transition et permanence, in: Cahiers du Centre d'Études sur l'Europe Médiane, Paris: Inalco, 1999, S. 55-64, hier S. 59.
} 
umgeben von den Ministern des Wohlfahrtsauschusses (Comité de salutpublic) im September 1848 mit gesenkten Häuptern und dunklen Mienen, welche die bevorstehende Niederlage andeuten $^{15}$. Die Reliefs zeigten Szenen aus den Kämpfen des Unabhängigkeitskrieges. ${ }^{16} 1945$ passte nun jene tragische und pessimistische Darstellung nicht zu dem vom kommunistischen Regime verbreiteten triumphierenden Optimismus. Somit wurde beschlossen, ein neues Denkmal in Auftrag zu geben, das 1952 von ZsigmondKisfaludyStróbl, András Kocsis und Lajos Ungvári fertiggestellt wurde. Eine Statue von Kossuth, fünf Meter hoch, mit dem rechten Arm gestreckt wie zu energischen Taten einladend, steht allein auf dem Sockel. Unterhalb, rechts und links, stürmen zwei Gruppen von Arbeitern, Bauern (darunter eine Frau) und Studenten zum Angriff. ${ }^{17}$ Im Rahmen der Umgestaltung des Platzes hat die OrbánRegierung das alte Denkmal rekonstruieren und wieder aufstellen lassen ${ }^{18}(\mathrm{Abb} .1+2)$.

float

../Bilder/Horel_01.jpgheight=78mm

Abb. 1

../Bilder/Horel_02.jpgheight=78mm

Abb. 2

Ein aufschlussreiches Element des ungarischen Geschichtsbewusstseins ist der Totenkult. Aufstände, Revolutionen, Kriege, Besetzungen, Horthy-Regime und Kommunismus haben in Ungarn seit dem 18. Jahrhundert eine beträchtliche Anzahl von Märtyrern, Selbstmördern und Exilanten hervorgebracht, die das imaginäre Pantheon des Nationalbewusstseins bevölkern. ${ }^{19}$ Deswegen war die Forderung nach anständigen Beerdigungen in Ungarn stärker als anderswo.

\footnotetext{
${ }^{15}$ Anachronismus und Fälschung charakterisierten schon damals den Diskurs, da einige Figuren gar nicht Mitglieder jenes Komitees gewesen waren, da sie sich von Kossuths Radikalismus distanziert und für einen Kompromiss mit Österreich ausgesprochen hatten, aber sie mussten trotzdem als Teilnehmer erscheinen. Das heutige Denkmal hat diese Interpretation nicht korrigiert.
}

${ }^{16}$ Gerö, March $15^{\text {th }}$, S. 119.

${ }^{17}$ Ebd., S. 121.

${ }^{18}$ Gleichzeitig wurde auch das Reiterstandbild von Gyula Andrássy am anderen Ende des Platzes wieder aufgestellt.

${ }^{19}$ Horel,Catherine: Le rôle de la sépulture politique dans la conscience collective hongroise, in: Mares, Antoine (Hrsg.): Les lieux de mémoire en Europe centrale, Paris: Institut d'études slaves, 2009, S.123 - 130. 
Den Märtyrern eine Ruhestätte zu geben, die ihrer nicht nur würdig, sondern dazu bestimmt ist, ein Ort der Erinnerung zu werden, bedeutet, die historische Wahrheit wiederherzustellen und die Konstruktion der nationalen Identität zu vervollständigen. Ungarn und seine politischen Führer, aber auch ihre Gegner praktizieren eine sogenannte „Politik am Rande des Grabes“( sírszelipolitika). Dieser Ausdruck, wahrscheinlich von Viktor Orbán selbst erfunden, wurde zuerst als Kritik an den erinnerungspolitischen Praktiken seines Vorgängers József Antall formuliert. Das Ritual entstand jedoch erstmals bereits 1870 anlässlich des Wiederbegräbnisses von Lajos Batthyány. Es wurde 1894 während der Rückführung der sterblichen Überreste von Lajos Kossuth, im Turiner Exil gestorben, perfektioniert. In ähnlicher Weise vollendete die Rückkehr des im Exil im Osmanischen Reich verstorbenen Fürsten Ferenc Rákóczi im Jahre 1906 das Ritual und machte es zu einem Teil des ungarischen Kollektivgedächtnisses. ${ }^{20}$ Das kommunistische Regime nahm diese Praxis wieder auf und organisierte bereits 1947 das Begräbnis der ungarischen Opfer des Faschismus ${ }^{21}$ den Nachruf sprach László Rajk, damaliger Innenminister und zukünftiges Opfer des Schauprozesses von 1949. In der Folge sollte das Ritual Teil des Anspruchs auf historische Wahrheit werden und am 6. Oktober 1956 zu Rajks offiziellem Begräbnis einen Auftakt des Aufstandes bilden.

Der große Budapester Friedhof von Rákoskeresztúr ist vor allem bemerkenswert im Hinblick auf seine Denkmäler für den Holocaust, sowie als Grabstätte von Soldaten aller Nationalitäten des Ersten Weltkriegs. Er war aber nach 1956 ein Ort des Verbergens, da die Leichen der während der Repression hingerichteten Personen in den Parzellen 298, 300 und 301 heimlich begraben wurden. Um die Mitte der 1980er-Jahre wurden Gerüchte immer lauter, wonach die Parzelle 301 die Überreste von Imre Nagy und seinen Mitangeklagten verbarg. Die erste Massenkundgebung fand am 16. Juni 1988 dort statt. Im darauffolgenden Herbst rammte die

\footnotetext{
${ }^{20}$ Das Zeremoniell wurde von József Antall anlässlich des Begräbnisses von Reichsverweser Horthy im September 1993 adaptiert und drei Monate später für seine eigene Trauerfeier durchgeführt. Vgl. Verdery, Katherine: The political lives of dead bodies. Reburial and post-socialist change, New York: Columbia University Press, 1999, S. 16.

${ }^{21}$ Im alten großen Friedhof von Kerepes, der bis heute als Pantheon der ungarischen Nation fungiert, errichteten die Kommunisten 1948 eine Grabstätte für ihre eigenen Helden, die bald als „Pantheon der Arbeiterklasse" bezeichnet wurde. Vgl. Apor, Péter: Immortalitas imperator: a Munkásmozgalmi Panteon születése [Die Errichtung des Pantheons für die Arbeiterbewegung], in: Aetas 2002, Nr. 2-3, unter: http://epa.oszk.hu/00800/00861/00022/2002-2-3-15.html (Stand: 18.07.2018).
} 
Dissidenten-Künstler-Gruppe Inconnu Holzpfähle (kopjafa) in der Parzelle ein. ${ }^{22}$ Im April 1989 wurde die Exhumierung der sterblichen Überreste von Nagy und seinen Mitangeklagten (Pál Maléter, Geza Losonczy, Miklós Gimes und József Szilágyi) schließlich durchgeführt; es war ein Vorspiel zu der Gedenkfeier und Bestattung vom 16. Juni 1989.

Die Revolution von 1956 erhielt sofort einen antisowjetischen Charakter: Das Emblem der Kommunistischen Partei wurde aus den Fahnen herausgerissen, um der Nationaltrikolore (rotweiß-grün) ihre ursprüngliche Bedeutung zu geben; Stalins Statue, als Repräsentation der Versklavung durch eine fremde Macht betrachtet, wurde von den Demonstranten zerstört und niedergeworfen. Die Entfaltung der Revolution und die Rückkehr zum Mehrparteiensystem verstärkten in der öffentlichen Meinung das Gefühl der Unzulänglichkeit Ungarns gegenüber dem kommunistischen Modell. Die unmittelbare Wiederbelebung der alten Parteien einschließlich der Sozialdemokratie - und der religiösen Organisationen zeigt, dass die Gesellschaft als Ganzes den Kommunismus ablehnt. Sie lehnt auch seine künstliche Konstruktion des Gedächtnisses ab, der sie die Permanenz ihres historischen Bewusstseins entgegenstellt. Die Anhänglichkeit an den alten Adel und das Landleben, die vom früheren Regime als höchste Werte errichtet wurden, sind in den Mentalitäten stärker verankert als die Kommunisten es geglaubt haben. Dieser Konservatismus schützt jedoch nicht nur vor der kommunistischen Ideologie, sondern assoziiert sie - in seiner Interpretation als ausländischer Beitrag - mit der städtischen, liberalen und multikulturellen Welt, hinter welcher der Antisemitismus zu spüren ist. Dieses Element wird von den Parteiführern sehr genau wahrgenommen, denn sie benutzen es, um den Aufstand als faschistisch zu brandmarken. Die Erinnerung an 1956 wird tabu; man spricht von den „Ereignissen“, die der Öffentlichkeit als imperialistische und zionistische Verschwörung präsentiert werden. Um das Gedenken an diese Episode zu verhindern, betont das Regime alle im Kalender bereits stattfindenden kommunistisch inspirierten Feierlichkeiten und gibt der Errichtung von Denkmälern und Statuen einen neuen Impuls. Diese Erinnerungspolitik des Kommunismus, die internationale Dimension und lokale Akteure verbindet, wird der Bevölkerung durch Schule und Pionierorganisation, die Presse und audiovisuelle Medien vermittelt. Die obligatorische Teilnahme an den Paraden vom 1. Mai und die anlässlich der Nationalfeiertage vom 4. April und 7. November verbreitete Propaganda tragen zur Gestaltung des kollektiven Gedächtnisses

\footnotetext{
${ }^{22}$ Ebd., S. 39. Der kopjafa ist ein ungarisches traditionelles Grabmal aus Holz ( $f a$ ), das ursprünglich von den Siebenbürger Szeklern verwendet wurde.
} 
bei. Im Raum durch Denkmäler und Statuen eingeschrieben, wird das kommunistische Regime in der Stadt durch die Toponomastik alltäglich lesbar: Namen von Straßen, U-BahnStationen, Stadien und anderen öffentlichen Gebäuden. Aber all diese Bemühungen erweisen sich als vergeblich, da die Bevölkerung an den alten Meilensteinen der Erinnerung festhält. Als die Heilige Krone 1978 nach Ungarn zurückgebracht wird, glaubt eine Wochenzeitung, innovativ zu sein, indem sie eine Umfrage über die Symbolhierarchie der Ungarn macht. Einfluss der Medien oder aufrichtige Loyalität, es ist genau die Krone, die zuerst genannt wird, während die Repräsentationen, die mit dem Regime in Verbindung stehen, ganz unten auf der Liste bleiben (zum Beispiel der rote Stern und die rote Flagge), selbst wenn sie mit nationalem Inhalt geschmückt sind. Es ist so, als ob die Bürger der Kommunistischen Partei das Recht verweigern, im Namen der Nation zu sprechen. Die Macht wird als illegitim und dem nationalen Bewusstsein entfremdet betrachtet, wobei sie vergeblich versucht, jene Elemente zu ihrem Nutzen zu erfassen. Die Bedeutung der Flagge ist bezeichnend für die von den Kommunisten betriebene „Usurpation“: eine der ersten Handlungen der Demonstranten am 23. Oktober 1956 bestand darin, das zentrale Motiv der Flagge zu entfernen, das für sie die Besetzung der Nation durch die Partei symbolisiert. Jene Wappen zeigten den roten Stern - mit der Sowjetunion identifiziert - umgeben von Hammer und Weizenähre, von Palmen umrahmt. Dieses Emblem sollte später nicht mehr auf der Flagge erscheinen. Die Flagge von 1956, mit dem Loch des „sowjetischen" Wappen in der Mitte, wurde zum Symbol der Revolte und der nationalen Unabhängigkeit: Es wurde 1989 wieder aufgenommen.

Die symbolische Dimension der Wende 1989 konzentriert sich ausschließlich auf die Anerkennung der Revolution von 1956 und die Huldigung ihrer Opfer. Die Erinnerung an den Kommunismus ist daher zunächst ein im Wesentlichen negatives, von Ressentiments getriebenes Gedächtnis. Die später an die Macht zurückkehrende Sozialistische Partei MSzP (1994-1998, 2002-2010) schämt sich ihrer eigenen Erinnerungspflicht. Die Revolution von 1956 ist weiterhin Gegenstand von Debatten und seine Instrumentalisierung je nach politischem Lager seit 1989 zu einer Konstante geworden. Die Rechte und die Linke beanspruchen eine Aneignung der Revolution, für welche jede einen Diskurs bereitstellt. Die neue sozialistische Partei zeigt sich gern „hemmungslos“ gegenüber jener Vergangenheit, weil sie angeblich nun aus Menschen besteht, die vor 1989 keine Verantwortung hatten, was natürlich nicht stimmt, denn viele sind zumindest Nachfahren von Parteibonzen. Sie verpflichtet sich jedoch, 1956 auch zu einem Element ihrer Gedächtnispolitik zu machen, indem sie den antistalinistischen Aspekt der Revolution ausnutzt und die sozial- 
demokratischen Persönlichkeiten hervorhebt. So war 2006 die Konfrontation zwischen dem linken und dem rechten Gedächtnis von 1956 am offensichtlichsten. Nach der ersten Runde der Parlamentswahlen vom April 2006 kommt der scheidende Premierminister Ferenc Gyurcsány auf den ersten Platz und lädt seine Anhänger zu einer Kundgebung rund um das Batthyány-Denkmal ein. ${ }^{23}$ Er will seine eigene Legitimität bestätigen, indem er sich mit dem Martyrium der beiden Premierminister (Batthyány und Nagy) vergleicht. Aber einige Monate später nimmt die Opposition die Gedenkfeiern zum 50. Jahrestag der Revolution zum Anlass für einen politischen Kampf. Es folgen wochenlange Demonstrationen, die von Ausschreitungen kleiner Gruppierungen geprägt sind, auf welche die Polizei mit Gewalt reagiert $^{24}$. Seitdem gedenken beide politische Lager der Revolution von 1956 mit eigenen Zeremonien, welche das gegenwärtige Machverhältnis reflektieren. Einen Beweis für jenes differenzierte, politisch konnotierte Gedächtnis stellt das neue Denkmal dar, welches genau an dem Ort, wo die Stalin-Statue stand, anlässlich der Gedenkfeier 2006 errichtet wurde (Abb. 3). Damals war die sozialistische Regierung von Ferenc Gyurcsány in einer sehr schwierigen Lage, so dass die Gedenkfeier von ihren Opponenten ausgenutzt wurde. Seitdem steht das Denkmal etwas vernachlässigt da, weil sein Diskurs jenem der aktuellen Regierung widerspricht. Weiterhin ist seine Lesbarkeit nicht eindeutig, da man von „Unabhängigkeitskrieg“ spricht, eine Bezeichnung, die den Kampf von 1848-49 kennzeichnet und nicht für 1956 verwendet werden kann, da sie historisch falsch ist.

../Bilder/Horel_03.jpg

Abb. 3

Die Repräsentation der Erinnerung an den Kommunismus, im Wesentlichen auf 1956 zentriert, ist mit dramatischen Merkmalen belegt. Der Hauptausdruck dieser

Überreizungstragödie ist im Diskurs des Terrorhauses (Terror Háza) zu erkennen, das sich im ehemaligen Sitz der politischen Polizei (der Pfeilkreuzler und des kommunistischen Regimes)

\footnotetext{
${ }^{23}$ Horel, Catherine: Les lieux de mémoire en Hongrie $\mathrm{XIX}^{\mathrm{e}}-\mathrm{XX}^{\mathrm{e}}$ siècles. Continuités et ruptures, in: Études Balkaniques, 2006/2, Sofia: Institut d'études balkaniques, Académie des sciences de Bulgarie, S.159 - 167.

${ }^{24}$ In diesem Kampf stellt der Kossuth-Platz hinter dem Parlament einen besonderen Streitpunkt dar. Gleich nach seinem Wahlsieg von 2010 machte Viktor Orbán die Umgestaltung jenes Platzes zu einem besonderen Ziel. Seitdem herrscht dort ein bewusst rechter Erinnerungsdiskurs: Das KárolyiDenkmal musste der Wiedererrichtung des 1934 inaugurierten Tisza-Denkmals weichen; das KossuthDenkmal wurde ebenfalls durch seine erste Variante von 1927 ersetzt, das ein völlig anderes Bild der 1848er-Revolution vermittelt; schließlich befinden sich auf dem Platz mehrere Denkmäler für die Revolution von 1956.
} 
in der Andrássy-Straße 60 befindet. Als eine Initiative der ersten Regierung von Viktor Orbán (1998-2002) und einer seiner Ratgeberinnen, der Historikerin Mária Schmidt, anvertraut, wurde das Museum sofort kritisiert. Seine Intention ist offensichtlich: Das Ausmaß der Unterdrückung und die Verbrechen des stalinistischen Regimes (1948-1953) sowie die Repression von 1956 zu zeigen. Theoretisch sollte das Haus des Terrors auch die Zeit des Horthy-Regimes illustrieren, es konzentriert sich aber de facto auf die Verbrechen der faschistischen Pfeilkreuzler während der deutschen Besatzung (Deutsche und Anhänger jener Partei vom März 1944 bis April 1945). Der Diskurs scheint also nicht nur beide Totalitarismen auf dieselbe Stufe zu setzen, sondern er wäscht auch das Horthy-Regime rein. Die Betonung des Emotionalen verhindert eine kritische historische Analyse im Haus des Terrors. Jene Fälschung und konsequente Verdrehung der Erinnerung ist bei dem 2014 errichteten Denkmal der deutschen Okkupation (németmegszállás) auf dem Szabadságtér (Freiheitsplatz) in Budapest am deutlichsten zu erkennen. Erstens wird hier die Verantwortung des ungarischen Staates verschwiegen, zweitens werden „Opfer“ gemeint, bei denen man nicht den Mut hat, sie zu nennen: die Juden. Ihnen sind andere Denkmäler gewidmet, antwortet die Regierung, was nur teilweise stimmt, weil sich die meisten in jüdischen Einrichtungen befinden (das jüdische Museum, das Holocaustzentrum in der Synagoge der Pava utca). Der anhaltende Protest am Ort, der ein „lebendiges“ Denkmal (elevenemlékmü) zu sein behauptet, sowie die Mediendebatte zeigen, dass die Öffentlichkeit auf die Manipulation des historischen Gedächtnisses aufmerksam geworden ist. (Abb. 4)

../Bilder/Horel_04.jpg

Abb. 4

Die spektakulärste Metamorphose der Wende ist jedoch das Verschwinden von Denkmälern und Statuen, die das kommunistische Regime Budapest geschenkt hatte. Die damnatio memoriae, die mit der Niederreißung der Stalin-Statue 1956 begann, wird nun fortgesetzt. Sie führt aber nicht zu einer vollständigen Zerstörung von Objekten, sondern organisiert ihre Verbannung in einen Statuen-Park (Szoborpark), der auf einem der Hügel von Budapest liegt, ziemlich weit entfernt vom Stadtzentrum. Die Entscheidung, jene Statuen und Denkmäler zu verlegen, wurde im Dezember 1991 vom Budapester Stadtrat gefällt. ${ }^{25}$ Gleichzeitig plant man die Ausstellung jener stummen Zeugen des sozialistischen Realismus. Der Park wurde im Juni

\footnotetext{
${ }^{25}$ Boros, Géza: Szoborpark[Der Statuen-Park], Budapest: Városháza, 2002, S. 5.
} 
1993 zum zweiten Jahrestag des Abzugs der sowjetischen Truppen aus Ungarn eröffnet. ${ }^{26}$ Seitdem wird die Anlage von Ungarn und Touristen besucht. Abgesehen von Flohmärkten, wo mehr oder weniger authentische Andenken und Medaillen aus der kommunistischen Ära verkauft werden, bildet derSzoborpark den einzigen Ort, wo eine gewisse Nostalgie spürbar ist, erhalten durch das Angebot an Mitbringseln für die jüngere Generation und westliche Touristen. Im Gegensatz zu anderen Ländern des ehemaligen Blocks gibt es in Ungarn praktisch keine Cafés oder Bars, die mit Relikten des alten Regimes geschmückt sind; in ähnlicher Weise hat die nostalgische Ironie des deutschen Films „Good bye, Lenin!“ keine Variante einer burlesken Erinnerung an die Kádár-Ära produziert. In dieser selektiven Erinnerung werden die Zwangsmaßnahmen und das Fehlen einer echten Alternative oft vergessen. Die Kontrolle über die Gesellschaft und insbesondere über die Jugend wird relativiert: Die alte Pionierbahn in Budapest wird beispielsweise in Betrieb gehalten, weil sie den Wanderwegen in den Hügeln dient, aber ohne ihre ehemalige politische Botschaft, deren Inhalt das Museum neben dem Abfahrtsbahnhof erwähnt, das aber kaum jemand besucht. ${ }^{27}$

Die Figur von János Kádár wird nicht besonders verehrt, erst 2003 erschien eine wissenschaftliche Biographie. ${ }^{28}$ Gelegentlich taucht er in Publikationen auf, wie im Fotoalbum „UnfinishedSocialism“ in einem eher wohlwollenden Licht. Genauso wie Franz Josef, der am Ende seines Lebens eher den Schutzpatron des Friedens und der Stabilität verkörperte, scheint die Öffentlichkeit Kádár seine Rolle bei der Repression von 1956 zu vergeben $^{29}$. Zwar gibt es nun eine Fülle wissenschaftlicher Arbeiten über den Kommunismus, doch dominiert Kádár nicht die historiographische Produktion, die sich mehr für die

\footnotetext{
${ }^{26}$ Ebd, S. 7.

${ }^{27}$ Jutteau, Kati: L'enfance embrigadée dans la Hongrie communiste. Le mouvement des pionniers, Paris: L'Harmattan, 2007, S.136 - 137.

${ }^{28}$ Huszár, Tibor: Kádár Jánospolitikai életrajza 1957-1989 [Die politische Biographie von JánosKádár 1957-1989], 2 Bände, Budapest: Szabad Tér, 2003. In der Nacht vom 1. Mai 2007 schändeten Unbekannte das Grab von János Kádár und seiner Frau auf dem Friedhof von Kerepes, ein äußerst seltenes Ereignis in Ungarn. Die öffentliche Meinung stieß sich an der Präsenz christlicher Symbole (Kruzifix) auf dem Grab.
}

\footnotetext{
${ }^{29}$ Horel, Catherine, János Kádár, le bâtisseur de la "baraque la plus gaie du camp, in Fabreguet, Michel, Henky, Danièle (Hg.), Les "héros du retrait" dans les mémoires et les représentations de l'Europe contemporaine. Histoire et fictions, Paris, L'Harmattan, 2020 S. 79-94.
} 
Zwischenkriegszeit und den Zweiten Weltkrieg interessiert. Publikationen, die sich an die breite Öffentlichkeit richten, konzentrieren sich ebenfalls auf diese Fragen und weniger auf die Bewertung des kommunistischen Regimes. ${ }^{30}$ Gleich nach seinem Tod am 6. Juli 1989 waren $75 \%$ der befragten Ungarn der Ansicht, dass das Land mit ihm eine seiner wichtigsten Persönlichkeiten verloren hatte. In einer Umfrage der späten 1990er-Jahre war Kádár für immer noch $42 \%$ der Ungarn der sympathischste (rokonszenves) Politiker des 20.

Jahrhunderts, während Imre Nagy nur $17 \%$ überzeugte. ${ }^{31}$

Das kommunistische Gedächtnis in Ungarn ist deshalb teilweise ausgelöscht, weil es keine linksextreme politische Kraft mehr gibt, die es beanspruchen könnte. Die von einigen Rentnern geäußerte Nostalgie spiegelt eher die materiellen Rahmenbedingungen des Regimes als seine ideologischen Inhalte oder seinen Erinnerungsdiskurs wider: Die Vollbeschäftigung wird vermisst, aber nicht die obligatorischen Paraden oder die Monumente des sozialistischen Realismus. Die Erinnerung an den Kommunismus hingegen wird zwischen der Dramatisierung der stalinistischen Jahre und dem Trauma von 1956 geteilt. Sie wird seit 2010 von der Regierung mit sehr starkem Akzent in Form der Gedenkfeiern, des Terrorhauses, der Denkmäler und einer Erinnerungspolitik betrieben, deren Diskurs sich global auf das vom kommunistischen Regime inkarnierte Böse konzentriert. Jene Politik zeigt jedoch ihre Grenzen auf der aktuellen politischen Bühne, wo der Mangel an „Entkommunisierung“ nach 1989 stigmatisiert wird. Diejenigen, die sich mit Recht empören, vergessen jedoch, dass Ungarn regelmäßig von „orientalischem“ Fieber befallen wird: Es besteht in der ungarischen Mentalität eine Konstante, wonach man dem Westen den Rücken zukehrt, zu Gunsten des mythisierten Turanismus, der an den uralischen Ursprung der Magyaren erinnert. Die Opposition zwischen Befürwortern des Westens und Anhängern einer östlichen Tradition ist seit dem Ende des 19. Jahrhunderts in das kollektive Bewusstsein eingeschrieben: Auf der einen Seite stehen die okzidentalisierten städtischen Eliten, auf der anderen Seite diejenigen, die das ländliche Leben, verkörpert von der ungarischen Tiefebene (möglichst in ihren

\footnotetext{
${ }^{30}$ Um nur zwei Beispiele der jüngeren Zeit zu erwähnen: Die Studien von Péter Kende, A kommunizmus és a magyar társadalom [Der Kommunismus und die ungarische Gesellschaft], Pozsony (Bratislava): Kalligram, 2013; Tabajdi, Gábor: Kiegyezés Kádárral «Szövetségi politika» 1956-1963 [Ausgleich mit Kádárs „Bündnispolitik“ 1956-1963], Budapest: Jaffa, 2013; Kérdések és válaszok a Kádárkorról [Fragen und Antworten über die Kádár-Zeit], Budapest: Napvilág, 2013.

${ }^{31}$ Romsics, Ignác: Volt egyszer egy rendszerváltás [Es war einmal eine Wende], Budapest: Rubicon könyvek, 2003, S. 164.
} 
ehemaligen königlichen Grenzen), als das Urwesen des Landes betrachten. Die

Wahrnehmung Russlands und damit des Kommunismus ist mit dieser Konstante verbunden:

Für manche bedeutet er die östliche Barbarei, für andere scheint er dem nationalen Charakter näher zu sein, der sich gen Osten neigt. Der Versuch, den Kommunismus zu einem Phänomen zu machen, das dem kollektiven Bewusstsein wesentlich fremd ist, kann jedoch in beiden politischen Lagern gefunden werden. Deswegen ist es manchmal schwierig, sein Gedächtnis in der ungarischen Gesellschaft zu analysieren.

\section{Die Erinnerung an das Horthy-Regime und die Pfeilkreuzler- Herrschaft}

Die Neubewertung von Miklós Horthy begann mit der Initiative der Chefs des Verlages Európa, die Erinnerungen des Reichsverwesers zum ersten Mal in Ungarn zu veröffentlichen. Der Prozess, der zu seinem Wiederbegräbnis führen sollte, war nun in Gang gesetzt. ${ }^{32}$ Die offizielle Initiative kam vom Verein der ungarischen Seeleute (Magyar tengerészekegyesülete), auf Anfrage seiner Schwiegertochter Ilona Edelsheim-Gyulai. ${ }^{33}$ Es war daher der Verein und nicht die Familie, die dem Ministerpräsidenten József Antall schrieb. Bevor das Außenministerium die Rückkehr der sterblichen Überreste von Horthy (und seiner Ehefrau sowie seines Sohnes Miklós) akzeptierte, entwickelte es ein Konzept, das dann als Grundlage für Verhandlungen bei allen anderen Anfragen dieser Art dienen sollte. Der erste Punkt greift die Tradition auf: Jeder Ungar hat das Recht, im magyarischen Land bestattet zu werden. Der zweite Punkt setzt fest, dass die Initiative von Privatpersonen (Familie oder Vereinigung) ausgehen muss. Der dritte und letzte Punkt besagt, dass der Staat sich dem Verfahren anschließen kann, indem er logistische und/oder materielle Hilfe leistet. In jenem Fall versuchte die Regierung jedoch, die Persönlichkeit Horthys zu ihren Gunsten zu nutzen, was sie jedoch nicht vor der Wahlniederlage im April 1994 bewahrte. Der krebskranke Antall ließ sich durch Innenminister und Mitglied des MDF Péter Boross vertreten, ${ }^{34}$ der sich verpflichtete, das Begräbnis zu einem Medienereignis zu machen.

\footnotetext{
${ }^{32}$ Zu der ganzen Episode vgl. Horel, Catherine: L'amiral Horthy, régent de Hongrie, Paris: Perrin, 2014, S. 402-406.

${ }^{33}$ Edelsheim Gyulai, Ilona: Becsület és kötelesség [Ehre und Pflicht], Budapest: Európa, Bd. 2, 20002001, S. 409.

34 József Antall starb am 12. Dezember 1993. Demzufolge amtierte Boross als Ministerpräsident bis zu den Wahlen von 1994.
} 
Die Regierungskommunikation betont den privaten Charakter der Trauerfeier, aber in der Tat geschieht das Gegenteil. Die Debatte in der Presse tobt um die Sinnhaftigkeit, den Reichsverweser wieder zu bestatten. Trotz der Versprechungen der Regierung wurde tatsächlich am 4. September 1993 eine offizielle Gedenkfeier abgehalten. Eine ungarische Armeeabteilung präsentierte das Gewehr in Anwesenheit von vier Ministern, zahlreicher Parlamentsmitglieder und József Antalls Ehefrau. Radio und Fernsehen übertrugen das Ereignis live; die nationale Währung veröffentlichte eine Gedenkmedaille. Die Menschenmenge in Kenderes wurde auf 70.000 Personen geschätzt.

Das Wiederbegräbnis bildete den wesentlichen Moment von Horthys „Rückkehr“ in das kollektive Bewusstsein Ungarns. Es war Teil eines Aufwertungsprozesses der Zwischenkriegszeit, dessen Mechanismus jedoch eine zweifache Reaktion auslöste. Historiker trugen dazu mit hochrangigen wissenschaftlichen Publikationen bei, beginnend mit IgnácRomsics mit seiner 1999 erschienenen Biographie des Grafen Bethlen. Seinem Beispiel folgten andere Historiker. Weitere biographische Werke wurden über die Persönlichkeiten des Horthy-Regimes verfasst: Eine Biographie über Gyula Gömbös von Jenő Gergely, einem Spezialisten der christlich-sozialen Bewegung ${ }^{35}$ die Arbeit von Balázs Ablonczy über Pál Teleki $^{36}$. In jüngerer Zeit konzentrierte sich das Interesse auf die ungarischen Pfeilkreuzler und den Nationalsozialismus, die ausführlich in der Arbeit von János Gyurgyák über die „Rassenverteidiger“ (Magyar fajvédők) und jene von Rudolf Paksa zum Nationalsozialismus in Ungarn erläutert wurden. ${ }^{37}$ Gleichzeitig vertiefte sich die Forschung über den Holocaust und die Verantwortung des Horthy-Regimes, unter anderen dank der Arbeiten von KrisztiánUngváry ${ }^{38}$, sowie über Horthy selbst und den Kult um ihn ${ }^{39}$. Somit stellt man sich

${ }^{35}$ Gergely, Jenő: Gömbös Gyula. Politikai pályakép [Gyula Gömbös. Politische Laufbahn], Budapest: Vince kiadó, 2001.

${ }^{36}$ Ablonczy, Balázs: Teleki Pál [Pál Teleki], Budapest: Osiris, 2005.

${ }^{37}$ Gyurgyák, János: Magyar fajvédők [Die ungarischen Rassenschützer], Budapest: Osiris, 2012; Paksa, Rudolf: Magyar nemzetiszocialisták. Az 1930-as évek új szélsőjobboldali mozgalma, pártjai, politikusai, sajtója [Die ungarischen Nationalsozialisten. Rechtsradikale Bewegungen, Parteien und Presse in den 1930er-Jahren], Budapest: Osiris, 2013.

38 Ungváry, Krisztián: A Horthy-rendszer mérlege. Diszkrimináció, szociálpolitika és antiszemitizmus Magyarországon [Die Bilanz des Horthy-Regimes. Diskriminierung, soziale Politik und Antisemitismus in Ungarn], Pécs: Jelenkor Kiadó, 2012.

${ }^{39}$ Turbucz, Dávid: A Horthy-Kultusz 1919-1944 [Der Horthy-Kultus 1919-1944], Budapest: MTA/TTI, 2016. 
auch Fragen über den Horthy-Mythos und vor allem über seine Haltung gegenüber den Juden und die nach der deutschen Invasion durchgeführten Deportationen, denen er sich endlich im Juli 1944 widersetzte. Der Historiker László Karsai untersucht und kritisiert den Mythos, wonach Horthy die Juden beschützt und gerettet habe ${ }^{40}$.

Die Debatte geht jedoch weit über akademische Kreise im engeren Sinne hinaus, da Historiker in Ungarn regelmäßig zu Fernsehsendungen eingeladen werden. Die Öffentlichkeit ist seit den 1980er-Jahren daran gewöhnt, die wichtigsten historischen Kontroversen zu verfolgen. Auch wenn das Interesse wirklich besteht und das Wissen relativ solide ist, führen die Medien trotzdem zwangsläufig zu einer extremen Vereinfachung der Argumente. Letztere werden auch im politischen Bereich wieder aufgenommen und verzerrt.

Das Horthy-Regime - und somit die Persönlichkeit des Regenten - ist Gegenstand vieler Diskussionen, von denen die erste das Wesen des Regimes betrifft. Die Arbeit der Historiker hat es ermöglicht, die Vulgata, die durch die kommunistische Geschichtsschreibung verbreitet wurden, zu revidieren, wonach es sich um einen Faschismus, sogar um einen „KlerikaloFaschismus“ handelte, entsprechend den Denkkategorien der 1950er-Jahre ${ }^{41}$. Die öffentliche Meinung hat jetzt den Unterschied zwischen der Regentschaft und den faschistischen und totalitären Diktaturen akzeptiert. Aber die Definition des Regimes ist immer noch problematisch, da es keine wirkliche Ideologie besaß. Diese Fragen erfordern eine gründliche Arbeit an den Konzepten und eine präzise Chronologie, die beide für das breite Publikum kaum zugänglich sind. Das Medieninteresse konzentriert sich daher auf Themen, die in Bezug auf Publikumswirksamkeit und Verkaufskraft als einfacher und vor allem erfolgversprechender angesehen werden. Dazu gehören vor allem der Antisemitismus und die Verantwortung Ungarns für die Umsetzung der Deportation. Es sind diese beiden Probleme, welche die öffentliche Meinung seit der Rückkehr von Viktor Orbán an die Macht mobilisieren. In diesem Kontext bewertet die Rechte das Horthy-Regime, in welchem sie irrtümlicherweise ein Modell sieht. Diese Analyse wird teilweise durch die

\footnotetext{
${ }^{40}$ Karsai, László: Horthy Miklós (1868-1957). Legendák, mítoszok és a valóság [Miklós Horthy (18681957). Legenden, Mythen und Realität], in: Beszélő, März 2007, S. 72-91.

${ }^{41}$ Romsics, Ignác: A Horthy-rendszer jellegéről. Historiográfiai áttekintés [Über die Natur des HorthyRegimes. Historiographische Untersuchung], in: Romsics, Ignác (Hrsg.): Múltról a mának. Tanulmányok és esszék a Magyar történelemről [Über die Vergangenheit für die Gegenwart. Studien und Essays zur ungarischen Geschichte], Budapest: Osiris, 2004, S. 339-357.
} 
antikommunistische Obsession der FIDESZ und ihres Führers erklärt, der der Ansicht ist, dass Ungarn noch nicht ausreichend von seiner Vergangenheit befreit sei. Rückblickend wird Horthy als Erneuerer und Garant der nationalen Unabhängigkeit betrachtet, und man vergisst dabei leicht die allmähliche Annäherung des Regimes an die Diktaturen. In diese Interpretation mischt sich ein gewisser Euroskeptizismus und eine antiwestliche Haltung, die eine Konstante der Wahrnehmung von Ungarns Stellung in Europa bildet. Orbán versucht dabei, Széchenyis Modernität und Offenheit mit Kossuths nationaler Unnachgiebigkeit in Einklang zu bringen. Dies gelingt ihm nur dank widersprüchlicher Aussagen, die manchmal für seine Wähler, manchmal für die Europäische Union gedacht sind.

Die jüngsten Arbeiten über Horthy, sein Regime und seine Zeit, tendieren in zwei Hauptrichtungen: Jene der Historiker fällen im Allgemeinen ein strenges Urteil über den Reichsverweser und seine Machtausübung. Gleichzeitig sind sie sich auch über den Kontext und die schwierige Lage Ungarns im Klaren und sehen den engen Spielraum, der Horthy zur Verfügung stand. Die Mittelmäßigkeit der politischen Elite war sicherlich ein erschwerender Faktor. Die populären Werke, Alben und andere Publikationen von schlechter Qualität sind hagiographisch, einige verherrlichen die Familie (trotz des fast völligen Mangels an Quellen) und andere verbreiten den Mythos wieder, der schon damals Horthy wie einen Helden und Retter der Nation präsentierte.

Als auch das Tabu von Trianon verschwand, assoziierte man schnell den Vertrag mit der Konterrevolution und der Machtübernahme von Horthy. Bei rechtsextremen Sympathisanten handelt es sich um ein Amalgam zwischen der Katastrophe von 1920 und dem HorthyRegime. Sie wiederholen die damalige Propaganda, die Horthy als den Retter der Nation und „Wiedergutmacher“ der Ungerechtigkeit des Vertrags darstellte. Selbstverständlich wollen sie nichts von historischer Kritik hören. Die Haltung der Antall-Regierung und der ersten OrbánRegierung (1998-2002) war in diesem Sinne zweideutig. Es ist unbestreitbar, dass die Rechte ihr Modell in der Zeit vor 1945 suchen musste, da sie seit der Gründung des kommunistischen Regimes nicht an der Macht beteiligt war. Trotz des historischen Bewusstseins der Ungarn war es schwierig, sich von den Führern des Ausgleiches 1867 oder gar von István Széchenyi inspirieren zu lassen. Letzterer diente zwar als unleugbare Referenz, hatte aber nie regiert und galt als Verlierer, somit konnte er kaum ein Modell für politische Aktion werden. Kossuth hingegen blieb weiterhin die Referenz der Linken und konnte nicht zugunsten der Rechten genutzt werden, was Orbán dennoch gerade in der letzten Zeit versucht. Die Wahl von Horthy 
war daher trotz der Kontroverse, die er sowieso verursachen würde, unerlässlich. Dies erklärt auch das relative Unbehagen der Regierung im Prozess des Wiederbegräbnisses.

Im Laufe der 1990er- und 2000er-Jahre kehrte die Figur von Horthy in den Medien immer wieder. Das Regime wird im Nationalmuseum (NemzetiMúzeum) sowie im Haus des Terrors dargestellt, aber einem kontrastierten Diskurs folgend, der die Debatte in der Gesellschaft widerspiegelt. Das Nationalmuseum gibt einen Überblick über die ungarische Geschichte von den Anfängen bis heute, die entsprechenden Ereignisse und Persönlichkeiten sind mehr oder weniger in Übereinstimmung mit der aktuellen Historiographie präsentiert. Das Haus des Terrors hingegen zeigt Horthy in einem positiven Licht, mit einem tendenziösen Diskurs, wonach das Böse erst unter der deutschen Besatzung begann. Das Verzeichnis der HorthyBilder, das IgnácRomsics in einem 2007 veröffentlichten Artikel vorgeschlagen hat, zählt die ehemaligen und heutigen negativen und positiven Interpretationen auf: Retter der Nation, Henker (der Weiße Terror), Verräter und Usurpator (die verpassten Restaurationsversuche Karls des IV.), Erbauer und Eroberer (die Revision), Zerstörer der Nation (1944), Patriot und Staatsoberhaupt. ${ }^{42}$ Jene Kategorien wurden abwechselnd von dem Horthy-Regime und seinen Gegnern verwendet, somit ist es nicht überraschend, dass sie noch jetzt in den Mentalitäten hängen geblieben sind. Sie werden regelmäßig anlässlich von Geburtstagen oder Wahlkampagnen reaktiviert.

Im Jahre 2006 drehte der Regisseur Gábor Koltay einen Dokumentarfilm über Horthy unter dem Titel A kormányzó (Der Reichsverweser). ${ }^{43}$ Man kann ihn als Nachtrag zu dem Film sehen, den Koltay 2004 dem Vertrag von Trianon widmete und dessen Sprache eine bloße Mystifizierung war. Der Horthy-Film bietet eine moderate Hagiographie, die die positiven Aspekte des Charakters hervorhebt und die Schatten bewusst verdeckt. Als wissenschaftliche Garanten dienen Historiker und Spezialisten anderer Disziplinen (Literatur, Wirtschaft), welche dem FIDESZ notorisch nahestehen. Die ausgewählten Zeugen sprechen alle zur

\footnotetext{
${ }^{42}$ Romsics, Ignác: Horthy-képeink [Unsere Horthy-Bilder], in: Romsics, Ignác (Hrsg.): Történelem, törtenetírás, hagyomány [Geschichte, Historiographie, Tradition], Budapest: Osiris, 2008, S. 213-252.

${ }^{43}$ In seinen jungen Jahren war Koltay ein Opponent des Regimes. Er wurde 1984 durch seinen Film über König Stefan (István, a király) bekannt, damals eine vom Regime wenig beachtete Figur. Durch seine Inszenierung der Gedenkfeier des 16. Juni 1989 wurde er ein Star. Nach der Wende wurde er immer nationalistischer und drehte 1996 einen Film über die ungarische Landnahme (Honfoglalás). Es folgten sehr umstrittene Dokumentarfilme über Trianon (2004) und Kardinal Mindszenty (Mindszenty, a fehér vértanú [Mindszenty, der weiße Märtyrer], 2010).
} 
Entlastung Horthys: Ilona Edelsheim-Gyulai und sein Sohn István, József Antall, der Bürgermeister von Kenderes und schließlich, um den Mythos von Horthy als Retter der Juden zu unterstreichen, ein ehemaliger jüdischer Bewohner von Preßburg. Die Botschaft ist klar: Horthy ist in allem, was ihm vorgeworfen werden kann, unschuldig. Der Weiße Terror war eine legitime Antwort auf den bolschewistischen Terror; Horthy hat 1944 die Juden gerettet. Neben seinem ehemaligen Premierminister István Bethlen tritt kaum eine andere politische Figur auf, an erster Stelle Gömbös, der nicht ins Bild passt. Kállay und Teleki werden nur mit einer Randbemerkung erwähnt. Das Bündnis mit Italien wird hervorgehoben, im Gegensatz zu jenem mit Deutschland. Der Ton des Films bleibt auf familiärer und emotionaler Ebene. Seit dem Amtsantritt der zweiten Orbán-Regierung im Mai 2010 ist Horthy nicht nur in der Debatte, sondern auch in Bildern präsent. Das Museum, das ihm in seinem Geburtsort Kenderes gewidmet ist, erhält weiterhin Gegenstände, welche an die populäre Ergebenheit der Zwischenkriegszeit erinnern. Die Miklós-Horthy-Gesellschaft (Horthy Miklós társaság) organisiert Gedenkfeiern, die eher mit Gleichgültigkeit und mit der pathetischen Teilnahme von immer weniger Veteranen verlaufen. ${ }^{44}$ Die Regierung geniert sich wegen der Inflation von Gedenkstätten, und Orbán verteidigt sich in den Medien, dieses Phänomen weder zu initiieren noch zu fördern. In einem Interview mit der österreichischen Tageszeitung „Die Presse“ tritt er hinter die Autonomie der lokalen Behörden zurück. Er weigert sich auch, Hitler, „einen Diktator, der unser Land besetzt hat“, auf die gleiche Ebene mit Horthy zu stellen, über dessen Interpretation er den Historikern das Wort zu überlassen verspricht ${ }^{45}$. Die neueren Initiativen der Erinnerungspolitik zeigen jedoch, dass die Regierung ihre eigene Agenda fortsetzt.

Projekte für neue Denkmäler werden regelmäßig von den Medien aufgedeckt und sorgen somit für Kontroversen. Ausländische Stimmen erheben sich ebenfalls, um die Erinnerung an Horthy und seine Heroisierung zu verurteilen. Der Direktor des Center forAdvanced Holocaust Studies am Holocaust-Museum in Washington (United States Holocaust Memorial Museum) Paul A. Shapiro sagte in einem Interview mit „Népszabadság“ im September 2012, dass er Horthy für schuldig halte, die Verfolgungen in Ungarn genehmigt zu haben und daher

\footnotetext{
${ }^{44}$ Horthy Miklós Társaság [Miklós-Horthy-Gesellschaft], unter: www.horthy.hu (Stand: 18.07.2018).

${ }^{45}$ Fleischhacker, Michael/Ultsch Christian: Orban im Interview: „Wir haben die Linke zertrümmert", in: Die Presse, 17. Juni 2012, S. 4-5.
} 
für unwürdig erachte, ein Standbild im öffentlichen Raum zu bekommen ${ }^{46}$. Trotz eines Schreibens des ungarischen Außenministers János Martonyi, die Regierung habe nicht die Absicht, Horthy-Statuen zu rehabilitieren, setzte Paul Shapiro seine Kritik an Ungarn fort. Er sprach vor dem amerikanischen Senat von der dubiosen Art, wie Ungarn des Holocausts gedenke. ${ }^{47}$ Jene Aussage ist charakteristisch für die amerikanische Haltung gegenüber den Ländern Mittel- und Osteuropas seit der Wende zur Demokratie. Die amerikanischen jüdischen Vertreter behaupten oft, die Behandlung des Holocausts in der Region beurteilen zu können, und sind überzeugt, dass ihre Expertise erwartet wird und unumgänglich ist. Sie sind aber mit den lokalen Realitäten nicht immer vertraut und ihre Einmischung wird manchmal fehlinterpretiert, sogar von der jüdischen Gemeinde. Paul Shapiro kritisiert zu Recht die ausfallenden Bemerkungen der Regierung Orbán und das Einverständnis einiger Persönlichkeiten der FIDESZ mit der extremen Rechten, gleichzeitig muss er auch erkennen, dass es gerade die erste Regierung Orbán war, welche die wichtigsten Institutionen zur Erinnerung und Erforschung des Holocaust geschaffen hat. Es ist eben jenes Paradox, das die Analyse der ungarischen Erinnerungspolitik erschwert. In Bezug auf die jüngsten Rehabilitationsprojekte zu Horthy zeigt sich Shapiro kompromisslos und setzt den Reichsverweser mit Adolf Hitler gleich. In ähnlicher Weise ist die Rückkehr einiger umstrittener Autoren in die literaturgeschichtlichen Lehrbücher sicherlich zu Recht verwerflich, aber jene minderwertigen Autoren sind nicht schlimmere Antisemiten als LouisFerdinand Céline. ${ }^{48}$

Tatsächlich hat Ungarn Schwierigkeiten mit seiner Vergangenheitsbewältigung, da es mit den Traumata des 20. Jahrhunderts nicht fertig wird. Dies zeigt eine von der linken Tageszeitung „Népszabadság“ im September 2012 organisierte Debatte über jene beiden Traumata, die laut IgnácRomsics entscheidend sind: der Trianon-Vertrag und die Verantwortung für die

\footnotetext{
46 „Távolítsák el a Horthy-emlékműveket!“ [Entfernen Sie die Horthy-Denkmäler!], in: Népszabadság, 10. September 2012, S. 13.

${ }^{47}$ Vgl. U.S. Senat: Anhörung von Paul Shapiro über Ungarn, in: The trajectory of democracy - why Hungary matters vom 19.03.2013, S. 27-31, unter:

https://www.csce.gov/sites/helsinkicommission.house.gov/files/The\%20Trajectory\%20of\%20Democracy\%20\%20Why\%20Hungary\%20Matters.pdf (Stand: 18.07.2018).

${ }^{48}$ Louis-Ferdinand Céline (1894-1961) ist einerseits einer der markantesten Autoren der Zwischenkriegszeit, andererseits bekannt für seine antisemitischen Pamphlete und seine Flucht nach Sigmaringen samt der kompromittiertesten Intellektuellen der Kollaboration. Nach dem Krieg wurde er für kurze Zeit in Dänemark interniert. 1951 wurde er amnestiert und kam zurück nach Frankreich.
} 
Judenverfolgung. Romsics macht zu Recht deutlich, dass beide Ereignisse zusammengehören, und erläutert die Grundzüge des Horthy-Regimes. ${ }^{49}$ Ähnlich liefert der Soziologe György Csepeli einen Beitrag über die „Horthy-Nostalgie“, die er selbstverständlich bei rechten und rechtsradikalen Politikern und Wählern aufspürt. ${ }^{50}$ Er ist auch zu Recht davon überzeugt, dass die heutigen Entscheidungsträger das Regime und den Reichverweser falsch interpretieren.

\section{Fazit}

Sowohl die Interpretation des Horthy-Regimes bleibt weiterhin problematisch als auch die der vierzig Jahre, die ihm folgten. Die Erinnerung an Horthy-Regime und Kommunismus ist in Ungarn deswegen untrennbar, weil sie der Sequenz 1919-1945-1956-1989 ihren Rhythmus gibt und der jeweiligen Ereignisse und Personen je nach Regime entweder gedacht wird oder sie verleugnet werden. Einige Historiker haben offensichtlich große Mühe damit, die notwendige Distanz zwischen ihrer persönlichen Erfahrung und ihrer Analyse der Zwischenkriegszeit herzustellen. Die Last des Schweigens und der Verfälschung der Geschichte durch das kommunistische Regime belastet noch immer die Mentalitäten. Die öffentliche Meinung neigt zu dem Gedanken, dass jenes, das verschwiegen wurde, unbedingt das Gegenteil von dem ist, das man sie zu glauben zwang. Der Opfermythos und der Hang zum Tragischen tragen dazu bei, eine extrem vereinfachte Vision jener Periode zu bewahren, die sicherlich komplex ist, heute aber von der Geschichtsschreibung in befriedigender Weise erforscht wird. Horthy dient also manchmal als Totem, manchmal als Vogelscheuche, je nach Lager, das ihn instrumentalisieren will. Damit ist er voll und ganz in das Pantheon umstrittener Figuren der ungarischen Geschichte eingetreten.

Die Stufen des historischen Gedächtnisses überlappen sich, da jedes Regime seit 1919 seine eigene Erinnerungspolitik durchgeführt hat, indem es systematisch die Denkmäler und Symbole des Vorigen zerstört, umgedeutet, geleugnet, verboten oder nur verschwiegen hat. Die demokratische Wende seit 1989 ermöglicht nun die Koexistenz mehrerer konkurrierender Diskurse in der Öffentlichkeit, wobei die von der Regierung allmählich konstruierten

\footnotetext{
${ }^{49}$ Romsics, Ignác: Trianon és a holokauszt. Huszadik századi traumáink [Trianon und der Holocaust. Unsere Traumata des 20. Jahrhunderts],in: Népszabadság, 1. September 2012, unter:http://nol.hu/belfold/20120901-huszadik_szazadi_traumaink (Stand:18.07.2018). Die Zeitung wurde 2016 eingestellt und nur ihr Archiv bleibt dem Leser zugänglich.

${ }^{50}$ Interview mit György Csepeli: Nincs Horthy-nosztalgia, csak a jobboldalon [Es gibt keine HorthyNostalgie, nur rechts], in: Héti Világgazdaság, 14. Juli 2012, S. 36-37.
} 
Erinnerungspraktiken einen eindeutig konservativen Tenor haben, der seine Inspiration aus jenem der Zwischenkriegszeit schöpft. Damit kommt es zu einer Unklarheit, die nicht geringer ist als zuvor, wenn nicht sogar zu bewussten Fälschungen, die man aber zumindest offenlegen und denen man widersprechen kann.

\section{Literatur}

Ablonczy, Balázs: Teleki Pál [Pál Teleki], Budapest: Osiris, 2005.

Apor, Péter: Immortalitasimperator: a MunkásmozgalmiPanteonszületése[Die Errichtung des Pantheons für die Arbeiterbewegung], in: Aetas 2002, Nr. 2-3, unter:

http://epa.oszk.hu/00800/00861/00022/2002-2-3-15.html (Stand: 18.07.2018).

Bakos, Katalin: Folyamatosságéstörés a plakátművészetben [Kontinuität und Bruch in der Plakatkunst], in: Standeisky, Éva et al. (Hrsg.): A fordulatévei 1947-1949. Politika, képzőművészet, építészet, Budapest: 1956-os Intézet, 1998.

Boros, Géza: Szoborpark[Der Statuen-Park], Budapest: Városháza, 2002.

Edelsheim Gyulai, Ilona: Becsületéskötelesség [Ehre und Pflicht], Budapest: Európa, Bd. 2, 2000-2001.

Fleischhacker, Michael/Ultsch Christian: „Orban im Interview: Wir haben die Linke zertrümmert“, in: Die Presse, 17. Juni 2012, S. 4-5.

Gergely, Jenő: Gömbös Gyula. Politikaipályakép [Gyula Gömbös. Politische Laufbahn], Budapest: Vince kiadó, 2001.

Gerö, András: March 15th: The Fortunes of a National Day, in: The New Hungarian Quarterly, Nr. 126, Bd. 33, Sommer 1992, S. 113-123.

Gyarmati, György: Márciushatalma, a hatalommárciusa. Fejezetekmárcius 15. ünneplésénektörténetéböl [Die Macht desMärz. Studien zur Geschichte der Feier zum 15. März], Budapest: Paginarum, 1998.

Gyurgyák, János: Magyar fajvédők [Die ungarischen Rassenschützer], Budapest: Osiris, 2012.

Halbwachs, Maurice: La mémoirecollective, Paris, Albin Michel, 1997. Deutsche Übersetzung: Das kollektive Gedächtnis, Stuttgart: Enke, 1967.

Horel, Catherine: Leslieux de mémoire à Budapest, entre transition et permanence, in: Cahiers du Centred'Étudessurl'EuropeMédiane, Paris: Inalco, 1999, S. 55-64. 
Horel, Catherine: Le rôle des lieux de mémoire dans la construction de la mémoirecollective en Hongrie, in: Nagy, Piroska (Hrsg.): Identités hongroises, identités européennes du Moyen Âge à nos jours, Publications des universités de Rouen et du Havre, 2006, S. 199-207.

Horel, Catherine: Leslieux de mémoire en Hongrie $\mathrm{XIX}^{\mathrm{e}}-\mathrm{XX}^{\mathrm{e}}$ siècles. Continuités et ruptures, in: Études Balkaniques, 2006/2, Sofia: Institut d'études balkaniques, Académie des sciences de Bulgarie, S.159 - 167.

Horel, Catherine: La récupération des cultures nationales: le cas de la Hongrie, in: Sirinelli, JeanFrançois/Soutou, Georges-Henri (Hrsg.): Culture et guerre froide, Paris: PUPS, 2008, S. 27-38.

Horel, Catherine: Le rôle de la sépulture politique dans la conscience collective hongroise, in: Mares, Antoine (Hrsg.): Les lieux de mémoire en Europe centrale, Paris: Institut d'études slaves, 2009, S.123 130.

Horel, Catherine: L'amiral Horthy, régent de Hongrie, Paris: Perrin, 2014.

Horel, Catherine: Die Repression gegen die Kirchen in Ungarn und der Tschechoslowakei, in: Gehler, Michael/Luif, Paul/Vyslonzil, Elisabeth (Hrsg.): Die Dimension Mitteleuropa in der Europäischen Union. Geschichte und Gegenwart, Historische Europa-Studien, Band 20, Hildesheim: Olms Verlag, 2015, S. 137 156.

Horthy Miklós Társaság [Miklós-Horthy-Gesellschaft], unter: www.horthy.hu (Stand: 18.07.2018).

Huszár, Tibor: Kádár Jánospolitikaiéletrajza 1957-1989 [Die politische Biographie von JánosKádár 19571989], 2 Bände, Budapest: SzabadTér, 2003.

Interview mit György Csepeli: Nincs Horthy-nosztalgia, csak a jobboldalon [Es gibt keine HorthyNostalgie, nur rechts], in HétiVilággazdaság, 14. Juli 2012, S. 36-37.

Jutteau, Kati: L'enfanceembrigadée dans la Hongrie communiste. Le mouvement des pionniers, Paris: L'Harmattan, 2007.

Karsai, László: Horthy Miklós (1868-1957). Legendák, mítoszokés a valóság [Miklós Horthy (1868-1957). Legenden, Mythen und Realität], in: Beszélö, März 2007, S. 72-91.

Kende, Péter: A kommunizmusés a magyartársadalom [Der Kommunismus und die ungarische Gesellschaft], Pozsony (Bratislava): Kalligram, 2013.

Paksa, Rudolf: Magyar nemzetiszocialisták. Az 1930-as évekújszélsőjobboldalimozgalma, pártjai, politikusai, sajtója [Die ungarischen Nationalsozialisten. Rechtsradikale Bewegungen, Parteien und Presse in den 1930er-Jahren], Budapest: Osiris, 2013. 
Romsics, Ignác: Magyarországtörténete a XX. században [Geschichte Ungarns im 20. Jahrhundert], Budapest: Osiris, 1999.

Romsics, Ignác: Volt egyszer egy rendszerváltás [Es war einmal eine Wende], Budapest: Rubiconkönyvek, 2003.

Romsics, Ignác: A Horthy-rendszerjellegéröl. Historiográfiaiáttekintés [Über die Natur des HorthyRegimes. Historiographische Untersuchung], in: Romsics, Ignác (Hrsg.): Múltról a mának. Tanulmányokésesszék a Magyar történelemröl [Über die Vergangenheit für die Gegenwart. Studien und Essays über die ungarische Geschichte], Budapest: Osiris, 2004, S. 339-357.

Romsics, Ignác: Horthy-képeink [Unsere Horthy-Bilder], in: Romsics, Ignác (Hrsg.): Történelem, törtenetírás, hagyomány [Geschichte, Historiographie, Tradition], Budapest: Osiris, 2008, S. 213252.

Romsics, Ignác: Trianon és a holokauszt. Huszadikszázaditraumáink [Trianon und der Holocaust. Unsere Traumata des 20. Jahrhunderts],in: Népszabadság, 1. September 2012, unter:

http://nol.hu/belfold/20120901-huszadik_szazadi_traumaink (Stand: 18.07.2018).

Tabajdi, Gábor: Kérdésekésválaszok a Kádárkorról [Fragen und Antworten über die Kádár-Zeit], Budapest: Napvilág, 2013.

Tabajdi, Gábor: KiegyezésKádárral «szövetségipolitika»1956-1963 [Ausgleich mit Kádárs „Bündnispolitik“ 1956-1963], Budapest: Jaffa, 2013.

„Távolítsákel a Horthy-emlékműveket! “ [Entfernen Sie die Horthy-Denkmäler!], in: Népszabadság, 10. September 2012, S. 13.

Turbucz,Dávid: A Horthy-Kultusz 1919-1944 [Der Horthy-Kultus], Budapest: MTA/TTI, 2016. Ungváry, Krisztián: Orte der Erinnerung an kommunistische Verbrechen. Das „Haus des Terrors“ und der „Zentralfriedhof", in: Weber, Matthias et al. (Hrsg.): Erinnerungsorte in Ostmitteleuropa.Erfahrungen der Vergangenheit und Perspektiven, München: Oldenbourg, 2011, S. 219-233.

Ungváry, Krisztián: A Horthy-rendszermérlege. Diszkrimináció, szociálpolitikaésantiszemitizmusMagyarországon [Die Bilanz des Horthy-Regimes. Diskriminierung, soziale Politik und Antisemitismus in Ungarn], Pécs: JelenkorKiadó, 2012.

U.S. Senat: Anhörung von Paul Shapiro über Ungarn, in: The trajectoryofdemocracy whyHungarymatters vom 19.03.2013, S. 27-31, unter:

https://www.csce.gov/sites/helsinkicommission.house.gov/files/The\%20Trajectory\%20of\%20Democracy\%20\%20Why\%20Hungary\%20Matters.pdf (Stand: 18.07.2018). 
Verdery, Katherine: The political lives of dead bodies. Reburial and post-socialist change, New York: Columbia University Press, 1999. 